\title{
Towards a macroscope: leveraging technology to transform the breadth, scale and resolution of macroecological data
}

Short title: Towards a macroscope

Article type: Macroecology 30th anniversary special issue

Keywords: biodiversity, monitoring, sampling design

Authors: $\quad$ Maria Dornelas ${ }^{1 *}$, Elizabeth M. P. Madin ${ }^{2}$, Michael Bunce ${ }^{3,4}$, Joseph D.

DiBattista $^{3,5}$, Mark Johnson ${ }^{1,6}$, Joshua S. Madin ${ }^{2}$, Anne E. Magurran ${ }^{1}$, Brian J. McGill ${ }^{7}$,

Nathalie Pettorelli ${ }^{8}$, Oscar Pizarro ${ }^{9}$, Stefan B. Williams ${ }^{89}$, Marten Winter ${ }^{9}$, Amanda E.

Bates ${ }^{11}$

\author{
Affiliations: \\ 1 - Centre for Biological Diversity, Scottish Oceans Institute, University of St Andrews \\ 2 - Hawai 'i Institute of Marine Biology, University of Hawai ‘i at Mānoa, Kaneohe, Hawai ‘i, USA \\ 3 - Trace and Environmental DNA (TrEnD) Laboratory, School of Molecular and Life Sciences, Curtin \\ University, Bentley, WA, 6102, Australia \\ 4 - Environmental Protection Authority, 215 Lambton Quay, Wellington 6011, New Zealand \\ 5 - Australian Museum Research Institute, Australian Museum, Sydney, NSW, 2010, Australia \\ 6 - Sea Mammal Research Unit, University of St Andrews \\ 7 - School of Biology and Ecology and Mitchell Center for Sustainability Solutions, University of Maine, United \\ States \\ 8- Institute of Zoology, Zoological Society of London, UK \\ 9 - Australian Centre for Field Robotics, University of Sydney, Australia \\ 10 - German Centre for Integrative Biodiversity Research (iDiv), Halle-Jena-Leipzig, Germany \\ 11 - Department of Ocean Sciences, Memorial University, Canada \\ * corresponding author emailmaadd@st-andrews.ac.uk
}

Acknowledgements: We are grateful to the editor and to F. Muller-Karger and Faye Moyes for helpful comments on the manuscript. Artwork for the figures is by Ana Bigio. MD is grateful for support from Templeton Foundation (grant \#60501, 'Putting the Extended Evolutionary Synthesis to the Test') and to from a Leverhulme Trust Fellowship.

data availability statement: no data are used in this paper.

Biosketch: This paper was written by a group of experts on the tools we propose would make up the macroscope. 


\begin{abstract}
The problem: Earth observations of the biosphere are spatially biased in ways that can limit our ability to detect macroecological patterns and biodiversity change. To resolve this problem we need to supplement ad hoc data currently collected, with planned biodiversity monitoring, in order to approximate global stratified random sampling of the planet. We call this all-encompassing observing system 'the macroscope'.
\end{abstract}

The solution: We identify seven main biosphere observation tools that compose the macroscope: satellites; drones; camera traps; passive acoustic samplers; biologgers; eDNA; and human observations. By deploying a nested array design of these tools that fills current gaps in monitoring, we can achieve a fit for purpose macroscope and turn these existing powerful tools into more than the sum of their parts.

An appeal: Building a macroscope requires commitment from multiple fields, together with coordinated actions to attract the level of funding required for such a venture. We call on macroecologists to become advocates for the macroscope and engage with existing global observation networks. 


\section{Introduction}

From its inception, macroecology has focused on using large datasets to establish general ecological laws (Brown \& Maurer, 1989). Macroecological studies are large on at least one of three axes - space, time or number of taxa (McGill et al., 2016) and show with data, rather than assert, that patterns are general and inferences about processes apply across a range of contexts. Macroecological laws can be about a variety of things, including the distribution in space and time of living organisms and organismal traits or how these distributions relate to environmental conditions and contribute to ecosystem function. Every field has a fundamental toolkit that produces the data necessary to put scientific laws to the test: astronomers have telescopes, weather forecasters have satellites and networks of ground instruments, and cell biologists have microscopes. In this paper, we argue that macroecology needs a macroscope: a toolkit that cohesively surveys biological diversity across the entire planet. We are not the first to make this argument. In the words of John Lawton:

\footnotetext{
"the fairy lacks a macroscope (...). Ecologists, too, lack a macroscope-a machine that reveals big patterns that emerge from a mass of local fuzz..."

(Lawton, 1996)
}

The need for a macroscope is made more urgent because of the massive transformation currently occurring in the biosphere. Ecologists agree that the planet is undergoing drastic and rapid changes in biodiversity, having even named the current epoch as the Anthropocene. However, the nature of these changes is controversial. On one hand, there are reports of unfolding "defaunation" (Dirzo et al., 2014), losses of 70\% of wildlife (LPI, 2016), "biological annihilation" (Ceballos et al., 2017), and an "insect armageddon" (Hallmann et al., 2017; Sánchez-Bayo \& Wyckhuys, 2019). On the other hand, there is evidence of "no net change of species richness" on average (Vellend et al., 2013; Dornelas et al., 2014), or evidence of local increases (Elahi et al., 2015), and of gains and losses being balanced (Dornelas et al., 2019). On both sides of the debate there are criticisms and counter-criticisms (e.g. (Gonzalez et al., 2016), vs. (Vellend et al., 2016); (Hallmann et al., 2017; Sánchez-Bayo \& Wyckhuys, 2019) vs. (Thomas et al., 2019)). An important point of contention is that the biodiversity data are taxonomically and spatially biased (Collen et al., 2009; Dornelas et al., 2018). Given the fact that biodiversity changes vary across biogeographical regions (Blowes et al., 2018), these biases can potentially limit our ability to detect global trends in diversity. 
However, these biases are common across global compilations of biodiversity data (Beck et $a l ., 2012$ ) and are likely driven by the distribution of scientists and funding (Meyer et al., 2016). Hence, to fully resolve these debates, we need a cohesive, planned approach for global biodiversity monitoring.

From a technical point of view, the timing is ripe to build a macroscope. Initial macroecological studies used almost exclusively human observations of organisms, but increasingly the types and volume of data are expanding. Technology is changing how we observe life on the planet, and tools like satellites, drones and underwater vehicles allow us to access parts of the planet that have been understudied and/or are not amenable to direct human observation. Automating some parts of biodiversity monitoring can facilitate the expansion process we are proposing, and instruments that detect the image, sound and chemical evidence of the presence of diverse life are expanding and becoming more broadly accessible. The macroscope should aim to leverage these tools to complement human observations, but maximising the transformative effect of these new approaches requires integrated design and deployment.

We propose a macroscope that will represent the biosphere of the entire planet in an unbiased manner, and hence should aim towards stratified random sampling at a planetary scale. However, there are significant differences between marine, freshwater and terrestrial realms in terms of accessibility to humans, observability, anthropogenic pressures (Bowler et al., 2018), and biodiversity change (Blowes et al., 2018). Air and water have vastly different chemical and physical properties and dynamics, which act to govern and constrain species' biology, ecology and evolution (Strathmann, 1990; Steele et al., 2018). Consequently, research questions, methods and data vary greatly across the aquatic-terrestrial interface, much more so than they do within realms. Although biodiversity observatories have much to gain from learning from experiences and practice across realms, the design of the macroscope will need to be tailored to each realm. The marine realm covers most of the planet $(70 \%)$ and is more volatile in conditions (Bates et al., 2018) and in its rate of biodiversity change (Blowes et al., 2018), yet most of the marine realm remains out of sight. In this paper, we focus specifically on the marine realm, while envisioning that the macroscope should function across the entire planet. 


\section{Design of a macroscope}

Unlike telescopes and microscopes, the macroscope is not a single tool. Rather, it is the integration of many tools that detect different things and at different resolutions. We envision the macroscope being like the networks of telescopes astronomers place strategically around the world to observe exoplanets continuously, or using different wavelengths that combine to form images. Because the biosphere varies so much in location, scale and signals that allow us to detect it, we require a variety of tools (Figure 1). Specifically, we identify seven interconnected component tools that can contribute complementary data to the macroscope: satellites; drones; camera traps; passive acoustic samplers; biologgers; eDNA; and human observations (Figure 1). These tools contribute to the biodiversity observing system, like different lenses contribute to a microscope. Below we describe each of these tools and what they contribute to the macroscope (Figure 2).

\section{Satellite data}

Satellites are the only of the tools explored here that allow truly global coverage of the surface of the planet. Since the first images of this blue marble we call planet Earth were taken from space a few decades ago, satellite remote sensing has evolved and expanded remarkably. Satellite remote sensing refers to the acquisition of information via satellitemounted sensors that measure the intensity of radiation in a particular range of the electromagnetic spectrum. Sensors on board satellites can monitor a range of radiations including visible light, near-infrared radiation (multi- and hyperspectral remote sensing; LiDAR) and microwave radiation (radar). The information that they capture is delivered in scenes (or images) which provide snapshots of a particular area at a particular time of the Earth's surface from above. Because different organisms, different parts of organisms, and parts in different states of health all show distinct reflection spectra, it is possible to tell much about biological systems just from light-based snapshots. These snapshots can be used to estimate many variables relevant to marine ecology and environmental management, including seascape change monitoring (e.g., change in distribution of coral reefs, sea grasses, and mangroves); climate change impact analysis; and tracking of anthropogenic pressures to biodiversity (such as eutrophication, fishing, oil spills and run-off; (Kachelriess et al., 2014)). There have been numerous notable recent reviews and books on the applications of RS for coastal managers (Miller et al., 2005; Klemas, 2010; Weng, 2010), coastal biodiversity 
indicators (Strittholt et al.), mangrove ecosystems (Kuenzer et al., 2011), seagrass meadows (Kirkman, 1996; Dekker et al., 2007), reef fish management (Hamel \& Andréfouët, 2010), shark and ray ecology (Williamson, 2018), and fisheries science (Klemas, 2013).

Satellite remote sensing is a fundamental component of the macroscope. Global products derived from the information captured by sensors on-board long-term satellite missions are widely accessible and offer a relatively inexpensive and verifiable means of deriving complete spatial coverage of environmental information for large areas in a consistent manner that may be updated regularly. Satellite imagery is the most effective means to provide the context of biodiversity, but it also has limitations. First, satellite remote sensingbased techniques can address spatial and temporal domains inaccessible to traditional, on the ground, approaches, but cannot match the accuracy, precision, and thematic richness of insitu measurements and regular monitoring. Satellites cannot "see" below a few metres, and so direct remote detection of most species in the sea is impossible using this technology alone. This has a direct analogue in meteorology where the global perspective of satellite imagery and the more accurate and fine scale measurements of ground instruments are essential complements to each other in the effort to track and predict weather. Large vertebrate marine species may be detectable from space, but the required imagery to do so can be expensive (Fretwell et al., 2014). The main limitations are cloud cover and the resolution of the imagery collected, but very high spatial resolution imagery (i.e., $<1 \mathrm{~m}$ ) is rapidly becoming more widely available (e.g., Planet's daily high-resolution whole-earth imaging).

\section{Drones, ROV and AUV Imagery}

To collect higher resolution imagery and access depths, observing tools need to be closer to the objects being observed. Drones, Remotely Operated Vehicles (ROVs) (Heifetz et al., 2009) and Autonomous Underwater Vehicles (AUVs) (Wynn et al., 2014) are robotic platforms that can carry camera payloads as well as navigation instruments and additional environmental sensors, and hence collect imagery and measure local environmental conditions over locally-extensive areas. They have been used extensively to collect in-situ imagery and water column information in support of the study of marine ecosystems. An important advantage of these unmanned tools is that they allow access to difficult locations including deepwater sites of significance in the areas of geothermal activities, at plate 
boundaries (Yoerger et al., 2007) as well as in extreme environments under ice (Jakuba et al., 2018)(A properly instrumented platform is able to provide georeferenced imagery by combining multiple navigation instruments such as depth (pressure sensor), orientation (attitude heading reference systems), speed over the bottom and absolute position.

Similar to satellite data, these tools can collect imagery across the radiation spectrum including stills and video of multispectral, hyperspectral and structured light. Given the closer proximity to the ecosystem being observed, the resolution of the imagery is much higher, which allows organisms to be identified within the ecosystem and to also quantify the structures they form. However, electromagnetic waves (including light) strongly attenuate in water (Kirk, 1977; Jaffe, 1990), with the maximum effective range (and footprint) for underwater imaging is a few meters, meaning that large-scale or even global coverage like above-surface remote sensing is not possible. These tools allow surveying at depth, where satellites cannot see, a critical point given that the mean depth of the oceans is $4 \mathrm{kms}$.

Therefore, these tools are integral to the macroscope in providing large but detailed snapshots of marine ecosystems and their inhabitants (Williams et al., 2012). However, they are not well suited for capturing mobile organisms because of the time-consuming processes involved in the surveys. Moreover, while in theory it is possible to automatically detect the organisms from this imagery, and great strides have been made in developing automated tools to streamline data processing, in practice the resolution and reliability of this detection process is still low and requires extensive human effort to go from the imagery to usable observations.

\section{Camera traps}

For even higher resolution imagery, and specifically for capturing mobile organisms, we can embed image collecting tools into the ecosystem. Camera traps remotely record still or video imagery of animals in their natural habitat. Like drones, these can be deployed at depth and have been instrumental in improving our understanding of both the pelagic zone and the deep sea. Camera traps have historically been cameras activated by an active or passive sensor (e.g., motion, infrared, light, etc.) (Caravaggi et al., 2017) but can also include non-triggered, continuous (i.e., video) cameras or cameras capturing imagery at specified intervals. 
Camera traps have two key advantages that make them essential parts of the macroscope. Camera traps are responsive to signals that an organism is present, making them well-suited to generating data on mobile species presence, diversity, distribution, and behaviour that is largely free of human influence. Second, camera traps require minimal time and effort to collect data (but with substantial post-hoc image processing).

Camera traps, hold great promise for marine science and conservation. They have been integral to observing the deep sea, but the development and mass production of affordable digital cameras have made them the most inexpensive of the tools described here. For example, their data may help establish baselines of species' populations; allow discovery of rare, threatened, or 'new' species; establish survival rates; and compare species' presence and behaviour across different places and times (e.g., inside vs. outside of marine protected areas; (Bond et al., 2012)). Although camera traps are fixed to a point, they record for a long period of time. This allows them to effectively sample across space for mobile organisms. And it also allows for temporal monitoring (e.g. phenology, ecosystem health) of immobile organisms.

A number of general limitations surround camera traps, such as providing a spatially- and temporally-limited scope of observation (i.e., the camera's field of view). Decreasing sizes and costs of cameras will allow greater numbers of cameras to be deployed to address this limitation. Battery and data storage limitations can be solved by advances in battery life and memory capacity. The current lack of standards for data management and sharing (Rowcliffe, 2017) could be alleviated with cheaper cloud-based data imagery storage and the development of universal standards.

The marine realm poses extra challenges. Physics dictate that heat- and motion-detection triggers do not work in aquatic environments where constant motion is the norm. Night time studies are particularly problematic: infrared radiation, which is invisible to fishes and needed for unobtrusive illumination, travels very little through water. Extremely low-light-sensing cameras paired with far-red illumination that is invisible to most fishes may help (Madin et al., 2019). Lastly, marine environments typically have low contrast and constant movement of particles, rendering automated image processing difficult. Optical back-scatter filters to improve image clarity (Mortazavi et al., 2013) hold promise, though some manual image processing will likely still be necessary. 


\section{Passive acoustic sampling}

Many marine organisms are only infrequently available for visual detection, but can be sensed by the sounds they produce. Hence surveying the soundscape is integral to a comprehensive macroscope. Passive acoustic monitoring (PAM) is used to determine the location, abundance, and density of vocal marine animals. Most aquatic mammals as well as some fish and invertebrates produce sounds that are distinctive enough to infer species from a high quality recording. The species richness of vocal animals as well as information about their habitat (Merchant et al., 2015) can therefore be deduced from sound recordings. Even silent animals can be monitored if tagged with acoustic transmitters that send coded signals. As sound propagates with low but frequency-dependent attenuation in water, animal sounds can be detected at ranges of 100's of metres (high frequencies) to 100's of km (low frequencies) (Richardson, 1995) giving far greater sensory volumes than for cameras albeit with less definitive information about each detection.

Acoustic monitors are widely deployed on moorings or towed from ships but are also increasingly finding applications in autonomous platforms such as gliders and drifters. Large scale PAM arrays (Carlén et al., 2018) can sample the spatial and temporal distribution of animals potentially in tandem with environmental forcing factors including human disturbance (McCarthy et al., 2011). However classification is challenging for species with similar calls or when dealing with rare species for which infrequent detections may be overwhelmed by false alarms from more abundant vocal species. Deep learning and citizen science are promising avenues for improving the cost-effectiveness of acoustic data processing. But there is also a need for more basic information from many species on individual call rates and characteristics to improve population estimates from acoustic detections.

\section{Biologgers}

Deciding how and when to deploy static sensors is an important element of all the tools discussed so far. Data gathered by sensors that move with an animal offer a Lagrangian complement (following an individual) to the Eulerian perspective of fixed macroscopic sensors. This type of sampling reveals, for example, how often prey are actually encountered by a predator as opposed to the prey resources potentially available at a particular location. Biologging involves the use of animal-attached sensors that collect data about the 
movements, activity level, behaviour, state of health, and immediate environment of individual animals. The need for tools to study aquatic animals that live most or all of their lives out of human sight has driven the development of increasingly sophisticated tags. Animal tags vary widely in their sensing capabilities from short duration multi-sensor devices with extremely high resolution that collect data about individual predatory events (Wisniewska et al., 2016) to tags that gather relatively sparse data over the entire lifetime of an animal (lifetime tag). A major factor affecting the choice of sensors, data rates, duration, and study species is whether data are stored on-board requiring recovery of the tag, or are telemetred making the tag disposable. As radio signals propagate poorly through salt water, radio telemetry (and GPS positioning) is only possible for animals that come to the surface, e.g., to breathe. Even so, the amount of data that can be transmitted from animals that are far from shore, requiring satellite telemetry, is extremely limited. For animals that never surface, low rate acoustic data telemetry is possible over short ranges but requires the installation of receiving moorings.

Miniature low-power sensing and data handling technology developed for consumer electronics has been a critical enabler of biologging devices. However, battery capacity remains a major constraint leading to their widest use on large animals that are capable of carrying relatively large devices. The advent of the Internet of Things (IoT) will expand the sensing, power harvesting and data telemetry options for biologging devices, making it feasible to study smaller species, in more detail, and for much longer.

\section{6. eDNA}

Sounds and images are not the only detectable evidence left by living organisms on the planet. Environmental DNA (eDNA) refers to all the genetic material that can be recovered from an environmental sample sourced from whole organisms such as bacteria or microeukaryotes, biological secretions such as blood or mucus, reproductive propagules, excretion, shed skin cells, hair or degrading tissue, or simply free DNA molecules (Taberlet et al., 2018). By compiling the information embedded within the DNA, we can begin to overcome the dependence on traditional biological surveys and taxonomic expertise, which rely heavily upon identifying whole organisms through their morphology. In contrast, the development of DNA barcode reference databases (e.g. GenBank or BOLD) coupled with advances in DNA sequencing technologies (i.e. next-generation sequencing, NGS) has catalysed the techniques 
known as 'metabarcoding'. Put simply, NGS has enabled DNA barcoding to transition from a focus on single organisms to multi-substrate biological samples such as seawater or sediment. The result of this advance is a significant improvement in our ability to generate powerful biological surveys of any environment that can be viewed under a macroscopic lens.

Metabarcoding of bacterial taxa using a conserved barcoding gene (16S rRNA) is a wellestablished method to survey prokaryotes and global-scale initiatives to deploy this approach are underway (Gilbert et al., 2014). The development of metabarcoding to survey eukaryotic systems, on the other hand, has lagged, but is now rapidly increasing (Jarman et al., 2018). This lag is due in part to the inconsistency in selecting amplifiable barcoding genes, lower concentrations of non-bacterial DNA isolated from environmental samples, and the paucity of reference databases, particularly those sourced from remote locations. The strength of eDNA-based approaches in this context are that it can 1) rapidly generate large volumes of sequence data (see (Taberlet et al., 2018) and references therein), 2) complement (but not replace) existing monitoring programs by identifying cryptic taxa missed by traditional survey methods (Stat et al., 2019), and 3) by combining assays, capture a broader range of phylogenetic diversity (i.e. Tree of Life Metabarcoding; (Stat et al., 2017)). Moreover, given the dilution of DNA (in seawater) coupled with high rates of DNA degradation in the environment, eDNA can often provide a localised ecological signature and short-lived "timestamp" of resident taxa (Stat et al., 2019), particularly if the extracted DNA is "biobanked" into long term storage (Jarman et al., 2018).

There are general limitations with eDNA metabarcoding that include: (i) a limited ability to relate DNA read frequency within a sample to species abundance within a sampling site, particularly for multi-species assays, (ii) taxonomic biases in DNA amplification, and (iii) incomplete DNA reference databases. This means that most eDNA studies, particularly those within the marine realm, often fall back on the relative safety of presence/absence data. Moreover, it is widely acknowledged that when using amplification approaches, some assays will fail to detect taxa of importance due to non-amplification of their DNA or failure to detect targets within the much larger microbial 'haystack'. Despite these limitations, eDNA is fast becoming an important part of the 'macroscope' that, with further refinement, will facilitate a powerful new age of ecological data generation across the tree of life.

\section{Human observations}


Humans started their early discovery of the world identifying species. Indeed, humans are exceptional at detecting differences in shape, size, contrast and sound. Perhaps it is this combination of a natural interest in the biological life forms with which we share our planet and our senses and reasoning capabilities that make humans excellent instruments for biodiversity observation. The numerical capacity of humans, combined with a wired world, means we are now connected at scales previously unimagined - translating to an unparalleled instrumental workforce on Earth.

We have centuries of human observations of biodiversity on the planet, and collating and curating these is an important component of the macroscope. In the past decade, numerous databases of expert observations have been compiled e.g. BioTIME (Dornelas et al., 2018), OBIS (Read et al., 2010), GBIF (GBIF, 2015) and LPI (LPI, 2016). In addition, some monitoring protocols have been deployed across many times and locations across the planet (e.g. Reef Life Survey (Edgar \& Stuart-Smith, 2014)). Many of the monitoring datasets included in these databases are ongoing and the macroscope will maximise their efficiency by complementing these efforts. In addition, citizen scientist observations can add to and further complement expert observations (Bird et al., 2014). Humans are instruments, and as we engage with the reality of 'big data', volunteers will be increasingly essential to growing the capacity to collect data through our everyday activities. With new technologies we have more data. Citizen scientists can also help with streamlining the process images and acoustic data, such as with the "Digital Fishers Program". Here, citizens screened images from an observatory camera at $1000 \mathrm{~m}$ (at the Oceans Network Canada), to identify those where a fish is present. The biggest limitation of human observations is that they are biased in frequency towards the time and spaces that humans occupy - i.e., humans are tied to land and primarily temperate and tropical climate zones.

\section{Data continuity}

One of the challenges of biodiversity assessment is that our view of variation in species abundances and identities over space and time is influenced by the lens through which we examine the systems involved. In principle, the concept of completely automated biodiversity data collection and analysis, implemented in an efficient way and with global reach, is extremely attractive. In practice, however, authoritative assessments of biodiversity patterns depend crucially on human input, to ensure that data collection is truly representative and 
consistent with the goals of the investigation(s), to oversee the handling and analyses of the data once collected, and to provide meaningful interpretation of the results.

The first important consideration is how data are collected, particularly what, how and where we sample. It is well known that different types of sampling methods will record different fractions of the assemblages of interest (Coddington et al., 1991; Sørensen et al., 2002). For example, samples of river fish collected using seining versus electro-fishing quantify different subsets of the diversity of the fish assemblage (Deacon et al., 2017). The time of day or season at which sampling takes place can also influence our perception of diversity in a locality (Grøtan et al., 2012). As such, comparative analyses have the potential to be influenced more strongly by differences in sampling methodology than by underlying variation in the diversity they seek to enumerate. A vast amount of experience about the strengths and weaknesses of different ecological methods has been built up over the years (Krebs, 1999; Southwood \& Henderson, 2000), and is reinforced through hands-on fieldwork. This expertise will play a key role in biodiversity assessment for the foreseeable future.

A second, and related, area in which human experts are irreplaceable is in providing continuity over time and space. To provide informed analysis of biodiversity change (Dornelas et al., 2014), for example, we need to make best use of long time series of biodiversity data, some of which - especially in earlier decades - were compiled using methods that are now recognised as flawed. The objectives of long term data collections can also change over time, sometimes to the extent that a new scheme is adopted. One way of dealing with this is to run old and new sampling schemes in parallel for a number of years, and measure the extent to which trends can be evaluated confidently in both (Magurran et al., 2010). Longer time series are also often affected by taxonomic revisions, and here again users are dependent on system experts to ensure that their analyses and conclusions are a fair reflection of the assemblages being monitored (Richardson et al., 2006).

A final issue is how we set the boundaries, in terms of space, time and taxonomic scope, of our assemblage of interest. This requires reflection and expert knowledge. For instance, temporal turnover means that while the numbers of species present at a given locality may be roughly constant over time, the species list will grow (Magurran \& Henderson, 2003). There are now powerful statistical tools that can be used to, for example, deduce the number of 
unseen species in rank-abundance distributions (Chao et al., 2015), but the effective application of these methods depends crucially on ecological knowledge. The macroscope is a much needed resource, but it will complement rather than replace humans as observers and interpreters of the Earth's biodiversity.

\section{The macroscope as more than the sum of its individual tools}

At the present time, biodiversity monitoring is spatially biased, leaving the majority of the world's oceans under-resourced and out of sight and out of mind (Richardson \& Poloczanska, 2008). Taxonomic biases are also well-acknowledged, with much more information on biodiversity gleaned from vertebrates, and particularly the species we harvest.

The technology required to monitor biodiversity across our global ocean at depth, within pelagic systems, at the poles, and across seasons to include times of the year which present access challenges (winter, monsoon, hurricane) exists. The infrastructure support for funding research operations in remote regions or times of the year that are hazardous to humans and instruments alike is expensive and difficult. To launch human and remotely operated vehicle expeditions and power instruments on the seafloor requires ship time to access sites and deploy instrument platforms, pilots for underwater vehicles, and technicians. Offshore and polar research expeditions also require field support teams to ensure health, safety and security of the researchers involved in these expeditions. These costs rapidly accumulate and therefore, to deploy our proposed macroscope, a strategic funding program is fundamental but it will require a paradigm shift in our thinking, scientific culture and research prioritization. Specifically, the macroscope requires much more integrated science, across disciplines, within ecology and across geographic borders.

The macroscope we propose aims to achieve better biodiversity monitoring by leveraging the strengths of each component tool in a nested, multi-scale design that approximates global stratified random sampling of the planet. Satellite imagery can document wholesale ecosystem-level changes (as least for the Earth's surface). This coarse grained classification of the planet should help define how to structure more detailed observations. To maximise our ability make inference, we should then randomise where within these stratified regions to deploy other tools. Other types of remote sensing, combined with human observations, can flag regions and taxa at risk that require urgent detailed observations to provide information that guides action. At specific locations, both at regular intervals and in response to changes, 
arrays of unmanned vehicles, camera traps, PAMs and eDNA sensors can be deployed to provide detailed and complementary information (Figure 2).

\section{Synthesising data across tools}

Data synthesis revolves around drawing together and analysing the vast range of data products to address questions of pressing importance. However, synthesis is challenging because data sources from different scientific fields and technologies are notoriously difficult to find and interpret (Reichman et al., 2011), let alone access and integrate into the streamlined analysis pipelines required for macroscopic synthesis (Schildhauer, 2018). Indeed, the more heterogeneous the data collected, and the newer the technology, the greater the chance of $a d$ hoc and disconnected data management approaches. However, amassing raw data from among and across levels of the macroscope into a centralized database is not ideal. Centralised data systems are not a practical solution for heterogeneous data (Jones et al., 2006) because they lack the flexibility for fast-evolving fields and technologies. Rather, the backbone of a macroscope should be a series of domain-specific data registries, set up and added to by the scientific communities that know their data products best.

The registry idea is not new. Metadata standards and repositories have been around for decades (Jones et al., 2006), but adoption is slow and sporadic. There is little incentive for busy researchers to use the repositories. Perhaps due to expense or efficiency, repositories tried to service whole disciplines (e.g., ecology). They were developed during the 1990s when ecologists were more protective of their data, and so the actual data sets associated with metadata are often not accessible. Essentially, smaller research groups and communities felt no ownership, and so no incentive to participate. Finally, and perhaps most importantly, examples of ground-breaking research emanating from repository initiatives remain rare.

The macroscope needs an alternative approach: smaller, flexible registries set up within domains by domain scientists. Like metadata repositories, registries would provide enough information for discovery based on attributes like location, time and, if applicable, taxonomy. Such registries should lead directly to the data — no roadblocks! — whether these data are supplemental to published papers and reports or large relational databases. Registries would not store data but would encourage data be stored in future-proof storage systems that will likely differ tremendously among disciplines. A registry would act as a conduit for communication and coordination among the various parts of the macroscope. Coordination 
might include development of handbooks for standard data collection methodologies, as well as standards for measurement units and common libraries of terms (Kissling et al., 2015; Navarro et al., 2017). Common terms would allow mapping among macroscope parts using logic (e.g., via ontological reasoning; (Madin et al., 2008). Moreover, common data structures and measurement standards across macroscope parts would guide data integration processes (GLOBIS-B, 2019). New technologies could easily plug-and-play with a flexible, connected, yet decentralized, data registry system. In summary, the connection between parts of the macroscope requires a light, flexible solution that is controlled by the research groups and communities that know them best. However, it should also ensure that data is accessible and can serve to link disparate data sources through a common registry-based conduit.

\section{An appeal to the field}

Most of the pieces to construct a macroscope exist, but to build a macroscope we need substantial funding, coordination and support from across different fields of ecology. Although ecology has always been the poor relative of the biological sciences, it is asked to answer some of the most pressing and relevant questions of humanity like how to achieve sustainable food and water provision. These are questions that transcend specific subfields and scientists, and can only be answered by everyone pulling in a similar direction. The exploration of the limits of the universe led to building of the Hubble telescope. The search for the boson led to building the large hadron collider. We believe that understanding how the biosphere is changing is one such question, and it can best be resolved by building a macroscope. Large scale assessments like the Millennium Ecosystem Assessment (Board, 2005) and the Intergovernmental Panel on Biodiversity and Ecosystem Services (IPBES) global assessment have highlighted the big challenges and societal impact of ecological research. Ecologists now have an audience, and therefore we must rise to the challenge and recognise the need for a shift from an individualist to a collectivist scientific culture.

The benefits of building a macroscope extend well beyond the field of macroecology, ecology and conservation biology. Arguably, the macroscope is essential to detect and avert global scale ecological collapse. Given signs of an unfolding mass extinction (Barnosky et al., 2011), such a detection system seems critical to protect the systems on which humans depend. The macroscope would allow macroecology to inform decision making regarding biodiversity from local to global scales. (Rapacciuolo, 2019) outlines how macroecological 
models can be more useful for management. Here we propose how more and better integrated data can help macroecology provide the basis of more informed biodiversity policy. If the IPBES is going to follow in the steps of the IPCC, biodiversity data needs better coverage and quality of observations through both space and time. It needs a global stratified random sampling of biodiversity across the planet. We argue that most of the parts for building the macroscope already exist, and hence the timing is ripe to build it. What is necessary is targeted substantial investment and structured coordination among the relevant research communities and funding agencies so that the whole can become more than the sum of its parts. Networks such as GEOBON, MBON and GOOS have the goal to build global observing system. In this paper we propose a vision for how this system could look like, and appeal to the field to engage with these networks and advocate in favour of a macroscope.

\section{References}

Barnosky, A.D., Matzke, N., Tomiya, S., Wogan, G.O., Swartz, B., Quental, T.B., Marshall, C., McGuire, J.L., Lindsey, E.L. \& Maguire, K.C. (2011) Has the Earth's sixth mass extinction already arrived? Nature, 471, 51.

Bates, A.E., Helmuth, B., Burrows, M.T., Duncan, M.I., Garrabou, J., Guy-Haim, T., Lima, F., Queiros, A.M., Seabra, R. \& Marsh, R. (2018) Biologists ignore ocean weather at their peril. In. Nature Publishing Group

Beck, J., Ballesteros-Mejia, L., Buchmann, C.M., Dengler, J., Fritz, S.A., Gruber, B., Hof, C., Jansen, F., Knapp, S. \& Kreft, H. (2012) What's on the horizon for macroecology? Ecography, 35, 673-683.

Bird, T.J., Bates, A.E., Lefcheck, J.S., Hill, N.A., Thomson, R.J., Edgar, G.J., Stuart-Smith, R.D., Wotherspoon, S., Krkosek, M. \& Stuart-Smith, J.F. (2014) Statistical solutions for error and bias in global citizen science datasets. Biological Conservation, 173, 144-154.

Blowes, S., Supp, S., Antao, L., Bates, A., Bruelheide, H., Chase, J., Moyes, F., Magurran, A., McGill, B., Myers-Smith, I., Winter, M., Bjorkman, A., Bowler, D., Byrnes, J.E., Gonzalez, A., Hines, J., Isbell, F., Jones, H., Navarro, L., Thompson, P., Vellend, M., Waldock, C. \& Dornelas, M. (2018) Biodiversity trends are stronger in marine than terrestrial assemblages. bioRxiv,

Board, M.A. (2005) Millennium ecosystem assessment. Washington, DC: New Island, 13

Bond, M.E., Babcock, E.A., Pikitch, E.K., Abercrombie, D.L., Lamb, N.F. \& Chapman, D.D. (2012) Reef sharks exhibit site-fidelity and higher relative abundance in marine reserves on the Mesoamerican Barrier Reef. PloS one, 7, e32983.

Bowler, D., Bjorkmann, A., Dornelas, M., Myers-Smith, I., Navarro, L., Niamir, A., Supp, S., Waldock, C., Vellend, M., Blowes, S., Boehning-Gaese, K., Bruelheide, H., Elahi, R., Antao, L., Hines, J., Isbell, F., Jones, H., Magurran, A., Cabral, J., Winter, M. \& Bates, A. (2018) The geography of the Anthropocene differs between the land and the sea. bioRxiv, 
Brown, J.H. \& Maurer, B.A. (1989) Macroecology: the division of food and space among species on continents. Science, 243, 1145-1150.

Caravaggi, A., Banks, P.B., Burton, A.C., Finlay, C.M., Haswell, P.M., Hayward, M.W., Rowcliffe, M.J. \& Wood, M.D. (2017) A review of camera trapping for conservation behaviour research. Remote Sensing in Ecology and Conservation, 3, 109-122.

Carlén, I., Thomas, L., Carlström, J., Amundin, M., Teilmann, J., Tregenza, N., Tougaard, J., Koblitz, J.C., Sveegaard, S., Wennerberg, D., Loisa, O., Dähne, M., Brundiers, K., Kosecka, M., Kyhn, L.A., Ljungqvist, C.T., Pawliczka, I., Koza, R., Arciszewski, B., Galatius, A., Jabbusch, M., Laaksonlaita, J., Niemi, J., Lyytinen, S., Gallus, A., Benke, H., Blankett, P., Skóra, K.E. \& Acevedo-Gutiérrez, A. (2018) Basin-scale distribution of harbour porpoises in the Baltic Sea provides basis for effective conservation actions. Biological Conservation, 226, 42-53.

Ceballos, G., Ehrlich, P.R. \& Dirzo, R. (2017) Biological annihilation via the ongoing sixth mass extinction signaled by vertebrate population losses and declines. Proceedings of the National Academy of Sciences, 114, E6089-E6096.

Chao, A., Hsieh, T., Chazdon, R.L., Colwell, R.K. \& Gotelli, N.J. (2015) Unveiling the species-rank abundance distribution by generalizing the Good-Turing sample coverage theory. Ecology, 96, 1189-1201.

Coddington, J.A., Griswold, C.E., Silva, D., Peñaranda, E. \& Larcher, S.F. (1991) Designing and testing sampling protocols to estimate biodiversity in tropical ecosystems. The Unity of Evolutionary Biology: Proceedings of the Fourth International Congress of Systematic and Evolutionary Biology, 2 vols (ed by.

Collen, B., Loh, J., Whitmee, S., McRae, L., Amin, R. \& Baillie, J.E.M. (2009) Monitoring Change in Vertebrate Abundance: the Living Planet Index. Conservation Biology, 23, 317-327.

Deacon, A.E., Mahabir, R., Inderlall, D., Ramnarine, I.W. \& Magurran, A.E. (2017)

Evaluating detectability of freshwater fish assemblages in tropical streams: Is handseining sufficient? Environmental Biology of Fishes, 100, 839-849.

Dekker, A., Brando, V., Anstee, J., Fyfe, S., Malthus, T. \& Karpouzli, E. (2007) Remote sensing of seagrass ecosystems: use of spaceborne and airborne sensors.

SEAGRASSES: BIOLOGY, ECOLOGYAND CONSERVATION, pp. 347-359. Springer.

Dirzo, R., Young, H.S., Galetti, M., Ceballos, G., Isaac, N.J.B. \& Collen, B. (2014) Defaunation in the Anthropocene. Science, 345, 401-406.

Dornelas, M., Gotelli, N.J., Shimadzu, H., Moyes, F., Magurran, A.E. \& McGill, B.J. (2019) A balance of winners and losers in the Anthropocene. Ecology Letters, $\mathbf{0}$

Dornelas, M., Gotelli, N.J., McGill, B., Shimadzu, H., Moyes, F., Sievers, C. \& Magurran, A.E. (2014) Assemblage Time Series Reveal Biodiversity Change but Not Systematic Loss. Science, 344, 296-299.

Dornelas, M., Antão Laura, H., Moyes, F., Bates Amanda, E., Magurran Anne, E., Adam, D., Akhmetzhanova Asem, A., Appeltans, W., Arcos José, M., Arnold, H., Ayyappan, N., Badihi, G., Baird Andrew, H., Barbosa, M., Barreto Tiago, E., Bässler, C., Bellgrove, A., Belmaker, J., Benedetti-Cecchi, L., Bett Brian, J., Bjorkman Anne, D., Błażewicz, M., Blowes Shane, A., Bloch Christopher, P., Bonebrake Timothy, C., Boyd, S., Bradford, M., Brooks Andrew, J., Brown James, H., Bruelheide, H., Budy, P., Carvalho, F., Castañeda-Moya, E., Chen Chaolun, A., Chamblee John, F., Chase Tory, J., Siegwart Collier, L., Collinge Sharon, K., Condit, R., Cooper Elisabeth, J., Cornelissen, J.H.C., Cotano, U., Kyle Crow, S., Damasceno, G., Davies Claire, H., Davis Robert, A., Day Frank, P., Degraer, S., Doherty Tim, S., Dunn Timothy, E., Durigan, G., Duffy, J.E., Edelist, D., Edgar Graham, J., Elahi, R., Elmendorf Sarah, 
C., Enemar, A., Ernest, S.K.M., Escribano, R., Estiarte, M., Evans Brian, S., Fan, T.Y., Turini Farah, F., Loureiro Fernandes, L., Farneda Fábio, Z., Fidelis, A., Fitt, R., Fosaa Anna, M., Daher Correa Franco Geraldo, A., Frank Grace, E., Fraser William, R., García, H., Cazzolla Gatti, R., Givan, O., Gorgone-Barbosa, E., Gould William, A., Gries, C., Grossman Gary, D., Gutierréz Julio, R., Hale, S., Harmon Mark, E., Harte, J., Haskins, G., Henshaw Donald, L., Hermanutz, L., Hidalgo, P., Higuchi, P., Hoey, A., Van Hoey, G., Hofgaard, A., Holeck, K., Hollister Robert, D., Holmes, R., Hoogenboom, M., Hsieh, C.-h., Hubbell Stephen, P., Huettmann, F., Huffard Christine, L., Hurlbert Allen, H., Macedo Ivanauskas, N., Janík, D., Jandt, U., Jażdżewska, A., Johannessen, T., Johnstone, J., Jones, J., Jones Faith, A.M., Kang, J., Kartawijaya, T., Keeley Erin, C., Kelt Douglas, A., Kinnear, R., Klanderud, K., Knutsen, H., Koenig Christopher, C., Kortz Alessandra, R., Král, K., Kuhnz Linda, A., Kuo, C.-Y., Kushner David, J., Laguionie-Marchais, C., Lancaster Lesley, T., Min Lee, C., Lefcheck Jonathan, S., Lévesque, E., Lightfoot, D., Lloret, F., Lloyd John, D., López-Baucells, A., Louzao, M., Madin Joshua, S., Magnússon, B., Malamud, S., Matthews, I., McFarland Kent, P., McGill, B., McKnight, D., McLarney William, O., Meador, J., Meserve Peter, L., Metcalfe Daniel, J., Meyer Christoph, F.J., Michelsen, A., Milchakova, N., Moens, T., Moland, E., Moore, J., Mathias Moreira, C., Müller, J., Murphy, G., Myers-Smith Isla, H., Myster Randall, W., Naumov, A., Neat, F., Nelson James, A., Paul Nelson, M., Newton Stephen, F., Norden, N., Oliver Jeffrey, C., Olsen Esben, M., Onipchenko Vladimir, G., Pabis, K., Pabst Robert, J., Paquette, A., Pardede, S., Paterson David, M., Pélissier, R., Peñuelas, J., Pérez-Matus, A., Pizarro, O., Pomati, F., Post, E., Prins Herbert, H.T., Priscu John, C., Provoost, P., Prudic Kathleen, L., Pulliainen, E., Ramesh, B.R., Mendivil Ramos, O., Rassweiler, A., Rebelo Jose, E., Reed Daniel, C., Reich Peter, B., Remillard Suzanne, M., Richardson Anthony, J., Richardson, J.P., van Rijn, I., Rocha, R., Rivera-Monroy Victor, H., Rixen, C., Robinson Kevin, P., Ribeiro Rodrigues, R., de Cerqueira RossaFeres, D., Rudstam, L., Ruhl, H., Ruz Catalina, S., Sampaio Erica, M., Rybicki, N., Rypel, A., Sal, S., Salgado, B., Santos Flavio, A.M., Savassi-Coutinho Ana, P., Scanga, S., Schmidt, J., Schooley, R., Setiawan, F., Shao, K.-T., Shaver Gaius, R., Sherman, S., Sherry Thomas, W., Siciński, J., Sievers, C., da Silva Ana, C., Rodrigues da Silva, F., Silveira Fabio, L., Slingsby, J., Smart, T., Snell Sara, J., Soudzilovskaia Nadejda, A., Souza Gabriel, B.G., Maluf Souza, F., Castro Souza, V., Stallings Christopher, D., Stanforth, R., Stanley Emily, H., Mauro Sterza, J., Stevens, M., Stuart-Smith, R., Rondon Suarez, Y., Supp, S., Yoshio Tamashiro, J., Tarigan, S., Thiede Gary, P., Thorn, S., Tolvanen, A., Teresa Zugliani Toniato, M., Totland, Ø., Twilley Robert, R., Vaitkus, G., Valdivia, N., Vallejo Martha, I., Valone Thomas, J., Van Colen, C., Vanaverbeke, J., Venturoli, F., Verheye Hans, M., Vianna, M., Vieira Rui, P., Vrška, T., Quang Vu, C., Van Vu, L., Waide Robert, B., Waldock, C., Watts, D., Webb, S., Wesołowski, T., White Ethan, P., Widdicombe Claire, E., Wilgers, D., Williams, R., Williams Stefan, B., Williamson, M., Willig Michael, R., Willis Trevor, J., Wipf, S., Woods Kerry, D., Woehler Eric, J., Zawada, K. \& Zettler Michael, L. (2018) BioTIME: A database of biodiversity time series for the Anthropocene. Global Ecology and Biogeography, 27, 760-786.

Edgar, G.J. \& Stuart-Smith, R.D. (2014) Systematic global assessment of reef fish communities by the Reef Life Survey program. Scientific Data, 1, 140007.

Elahi, R., O’Connor, M.I., Byrnes, J.E., Dunic, J., Eriksson, B.K., Hensel, M.J. \& Kearns, P.J. (2015) Recent trends in local-scale marine biodiversity reflect community structure and human impacts. Current Biology, 25, 1938-1943. 
Fretwell, P.T., Staniland, I.J. \& Forcada, J. (2014) Whales from Space: Counting Southern Right Whales by Satellite. PLOS ONE, 9, e88655.

GBIF (2015) http://www.gbif.org/.

Gilbert, J.A., Jansson, J.K. \& Knight, R. (2014) The Earth Microbiome project: successes and aspirations. BMC biology, 12, 69.

GLOBIS-B (2019) http://www.globis-b.eu/. Accessed 2019.

Gonzalez, A., Cardinale, B.J., Allington, G.R.H., Byrnes, J., Endlsey, K.A., Brown, D.G., Hooper, D.U., Isbell, F., O'Connor, M.I. \& Loreau, M. (2016) Estimating local biodiversity change: a critique of papers claiming no net loss of local diversity. Ecology, 97, 1949-1960.

Grøtan, V., Lande, R., Engen, S., Sæther, B.E. \& DeVries, P.J. (2012) Seasonal cycles of species diversity and similarity in a tropical butterfly community. Journal of Animal Ecology, 81, 714-723.

Hallmann, C.A., Sorg, M., Jongejans, E., Siepel, H., Hofland, N., Schwan, H., Stenmans, W., Müller, A., Sumser, H., Hörren, T., Goulson, D. \& de Kroon, H. (2017) More than 75 percent decline over 27 years in total flying insect biomass in protected areas. PLOS $O N E, \mathbf{1 2}, \mathrm{e} 0185809$.

Hamel, M.A. \& Andréfouët, S. (2010) Using very high resolution remote sensing for the management of coral reef fisheries: Review and perspectives. Marine pollution bulletin, 60, 1397-1405.

Heifetz, J., Stone, R.P. \& Shotwell, S.K. (2009) Damage and disturbance to coral and sponge habitat of the Aleutian Archipelago. Marine Ecology Progress Series, 397, 295-303.

Jaffe, J.S. (1990) Computer modeling and the design of optimal underwater imaging systems. IEEE Journal of Oceanic Engineering, 15, 101-111.

Jakuba, M.V., German, C.R., Bowen, A.D., Whitcomb, L.L., Hand, K., Branch, A., Chien, S. $\&$ McFarland, C. (2018) Teleoperation and robotics under ice: Implications for planetary exploration. 2018 IEEE Aerospace Conference (ed by, pp. 1-14.

Jarman, S.N., Berry, O. \& Bunce, M. (2018) The value of environmental DNA biobanking for long-term biomonitoring. Nature ecology \& evolution, 2, 1192.

Jones, M.B., Schildhauer, M.P., Reichman, O. \& Bowers, S. (2006) The new bioinformatics: integrating ecological data from the gene to the biosphere. Annual Review of Ecology, Evolution, and Systematics, 37

Kachelriess, D., Wegmann, M., Gollock, M. \& Pettorelli, N. (2014) The application of remote sensing for marine protected area management. Ecological Indicators, 36, $169-177$.

Kirk, J.T.O. (1977) Attenuation of light in natural waters. Marine and Freshwater Research, 28, 497-508.

Kirkman, H. (1996) Baseline and monitoring methods for seagrass meadows. Journal of Environmental Management, 47, 191-201.

Kissling, W.D., Hardisty, A., García, E.A., Santamaria, M., De Leo, F., Pesole, G., Freyhof, J., Manset, D., Wissel, S., Konijn, J. \& Los, W. (2015) Towards global interoperability for supporting biodiversity research on essential biodiversity variables (EBVs). Biodiversity, 16, 99-107.

Klemas, V. (2010) Remote sensing techniques for studying coastal ecosystems: An overview. Journal of Coastal Research, 27, 2-17.

Klemas, V. (2013) Fisheries applications of remote sensing: an overview. Fisheries Research, 148, 124-136.

Krebs, C.J. (1999) Ecological methodology, 2nd edition edn. Harper \& Row.

Kuenzer, C., Bluemel, A., Gebhardt, S., Quoc, T.V. \& Dech, S. (2011) Remote sensing of mangrove ecosystems: A review. Remote Sensing, 3, 878-928. 
Lawton, J.H. (1996) Patterns in Ecology. Oikos, 75, 145-147.

LPI (2016) Living Planet Index database. 2017. Downloaded June 2018. www.livingplanetindex.org/. In:

Madin, E., Precoda, K., Harborne, A., Atwood, T.B., Roelfsema, C.M. \& Luiz, O. (2019) Multi-trophic species interactions shape seascape-scale coral reef vegetation patterns. Frontiers in Ecology and Evolution, 7, 102.

Madin, J.S., Bowers, S., Schildhauer, M.P. \& Jones, M.B. (2008) Advancing ecological research with ontologies. Trends in ecology \& evolution, 23, 159-168.

Magurran, A.E. \& Henderson, P.A. (2003) Explaining the excess of rare species in natural species abundance distributions. Nature, 422, 714.

Magurran, A.E., Baillie, S.R., Buckland, S.T., Dick, J.M., Elston, D.A., Scott, E.M., Smith, R.I., Somerfield, P.J. \& Watt, A.D. (2010) Long-term datasets in biodiversity research and monitoring: assessing change in ecological communities through time. Trends in ecology \& evolution, 25, 574-582.

McCarthy, E., Moretti, D., Thomas, L., DiMarzio, N., Morrissey, R., Jarvis, S., Ward, J., Izzi, A. \& Dilley, A. (2011) Changes in spatial and temporal distribution and vocal behavior of Blainville's beaked whales (Mesoplodon densirostris) during multiship exercises with mid-frequency sonar. Marine Mammal Science, 27, E206-E226.

McGill, B.J., Dornelas, M. \& Field, R. (2016) A new year with a new leadership team at GEB - or how to guarantee your paper gets into GEB. Global Ecology and Biogeography, 25, 1-2.

Merchant, N.D., Fristrup, K.M., Johnson, M.P., Tyack, P.L., Witt, M.J., Blondel, P. \& Parks, S.E. (2015) Measuring acoustic habitats. Methods in Ecology and Evolution, 6, 257265.

Meyer, C., Jetz, W., Guralnick, R.P., Fritz, S.A. \& Kreft, H. (2016) Range geometry and socio-economics dominate species-level biases in occurrence information. Global Ecology and Biogeography, 25, 1181-1193.

Miller, R.L., Del Castillo, C.E. \& McKee, B.A. (2005) Remote sensing of coastal aquatic environments. Springer.

Mortazavi, H., Oakley, J.P. \& Barkat, B. (2013) Mitigating the effect of optical back-scatter in multispectral underwater imaging. Measurement Science and Technology, 24, 074025.

Navarro, L.M., Fernández, N., Guerra, C., Guralnick, R., Kissling, W.D., Londoño, M.C., Muller-Karger, F., Turak, E., Balvanera, P., Costello, M.J., Delavaud, A., El Serafy, G.Y., Ferrier, S., Geijzendorffer, I., Geller, G.N., Jetz, W., Kim, E.-S., Kim, H., Martin, C.S., McGeoch, M.A., Mwampamba, T.H., Nel, J.L., Nicholson, E., Pettorelli, N., Schaepman, M.E., Skidmore, A., Sousa Pinto, I., Vergara, S., Vihervaara, P., Xu, H., Yahara, T., Gill, M. \& Pereira, H.M. (2017) Monitoring biodiversity change through effective global coordination. Current Opinion in Environmental Sustainability, 29, 158-169.

Rapacciuolo, G. (2019) Strengthening the contribution of macroecological models to conservation practice. Global Ecology and Biogeography, 28, 54-60.

Read, A., Halpin, P., Crowder, L., Best, B. \& Fujioka, E. (2010) OBIS-SEAMAP: mapping marine mammals, birds and turtles. World Wide Web electronic publication. http://seamap. env. duke. edu,

Reichman, O.J., Jones, M.B. \& Schildhauer, M.P. (2011) Challenges and opportunities of open data in ecology. Science, 331, 703-705.

Richardson, A., Walne, A., John, A., Jonas, T., Lindley, J., Sims, D., Stevens, D. \& Witt, M. (2006) Using continuous plankton recorder data. Progress in Oceanography, 68, 27 74. 
Richardson, A.J. \& Poloczanska, E.S. (2008) Under-resourced, under threat. In. American Association for the Advancement of Science

Richardson, W. (1995) Measurement procedures, Chapter 3. IN Richardson, WJ. CR Greene Jr., CI Malme, and DH Thomson. 1995a. Marine Mammals and Noise. In. Academic Press, San Diego. 576p

Rowcliffe, J.M. (2017) Key frontiers in camera trapping research. Remote Sensing in Ecology and Conservation, 3, 107-108.

Sánchez-Bayo, F. \& Wyckhuys, K.A.G. (2019) Worldwide decline of the entomofauna: A review of its drivers. Biological Conservation, 232, 8-27.

Schildhauer, M. (2018) Data Integration: Principles and Practice. Ecological Informatics, pp. 129-157. Springer.

Sørensen, L.L., Coddington, J.A. \& Scharff, N. (2002) Inventorying and estimating subcanopy spider diversity using semiquantitative sampling methods in an Afromontane forest. Environmental Entomology, 31, 319-330.

Southwood, T. \& Henderson, P. (2000) Ecological Methods. 3rd edn. 575 pp. In. Oxford, Blackwell Science

Stat, M., John, J., DiBattista, J.D., Newman, S.J., Bunce, M. \& Harvey, E.S. (2019) Combined use of eDNA metabarcoding and video surveillance for the assessment of fish biodiversity. Conservation Biology, 33, 196-205.

Stat, M., Huggett, M.J., Bernasconi, R., DiBattista, J.D., Berry, T.E., Newman, S.J., Harvey, E.S. \& Bunce, M. (2017) Ecosystem biomonitoring with eDNA: metabarcoding across the tree of life in a tropical marine environment. Scientific Reports, 7, 12240.

Steele, J.H., Brink, K.H., Scott, B.E. \& Browman, H.e.H. (2018) Comparison of marine and terrestrial ecosystems: suggestions of an evolutionary perspective influenced by environmental variation. ICES Journal of Marine Science, 76, 50-59.

Strathmann, R.R. (1990) Why life histories evolve differently in the sea. American Zoologist, 30, 197-207.

Strittholt, J., Miles, L., Horning, N. \& Fosnight, E. SourCeBook oN remoTe SeNSiNg aND BioDiverSiTy iNDiCaTorS.

Taberlet, P., Bonin, A., Zinger, L. \& Coissac, E. (2018) Environmental DNA: For biodiversity research and monitoring. Oxford University Press.

Thomas, C.D., Jones, T.H. \& Hartley, S.E. (2019) “Insectageddon”: A call for more robust data and rigorous analyses. Global Change Biology, 0

Vellend, M., Baeten, L., Myers-Smith, I.H., Elmendorf, S.C., Beauséjour, R., Brown, C.D., De Frenne, P., Verheyen, K. \& Wipf, S. (2013) Global meta-analysis reveals no net change in local-scale plant biodiversity over time. Proceedings of the National Academy of Sciences, 110, 19456-19459.

Vellend, M., Dornelas, M., Baeten, L., Beauséjour, R., Brown, C.D., De Frenne, P., Elmendorf, S.C., Gotelli, N.J., Moyes, F., Myers-Smith, I.H., Magurran, A.E., McGill, B.J., Shimadzu, H. \& Sievers, C. (2016) Estimates of local biodiversity change over time stand up to scrutiny. Ecology, n/a-n/a.

Weng, Q. (2010) Remote sensing of coastal environments. Taylor and Francis Ltd.

Williams, S.B., Pizarro, O.R., Jakuba, M.V., Johnson, C.R., Barrett, N.S., Babcock, R.C., Kendrick, G.A., Steinberg, P.D., Heyward, A.J., Doherty, P.J., Mahon, I., JohnsonRoberson, M., Steinberg, D. \& Friedman, A. (2012) Monitoring of Benthic Reference Sites: Using an Autonomous Underwater Vehicle. IEEE Robotics \& Automation Magazine, 19, 73-84.

Williamson, P. (2018) Biodiversity risks of climate control. Nature Ecology \& Evolution, Wisniewska, D.M., Johnson, M., Teilmann, J., Rojano-Doñate, L., Shearer, J., Sveegaard, S., Miller, L.A., Siebert, U. \& Madsen, P.T. (2016) Ultra-high foraging rates of harbor 
porpoises make them vulnerable to anthropogenic disturbance. Current Biology, 26, 1441-1446.

Wynn, R.B., Huvenne, V.A.I., Le Bas, T.P., Murton, B.J., Connelly, D.P., Bett, B.J., Ruhl, H.A., Morris, K.J., Peakall, J., Parsons, D.R., Sumner, E.J., Darby, S.E., Dorrell, R.M. \& Hunt, J.E. (2014) Autonomous Underwater Vehicles (AUVs): Their past, present and future contributions to the advancement of marine geoscience. Marine Geology, 352, 451-468.

Yoerger, D.R., Jakuba, M., Bradley, A.M. \& Bingham, B. (2007) Techniques for Deep Sea Near Bottom Survey Using an Autonomous Underwater Vehicle. The International Journal of Robotics Research, 26, 41-54.

Data accessibility statement: no data are used in this paper 
Figure 1: The macroscope is composed of seven tools integrated to detect a variety of signals of life. The diversity of organisms to be surveyed and the range of relevant spatial and temporal scales required for appropriate biodiversity monitoring justify the need for the integration of these multiple tools.

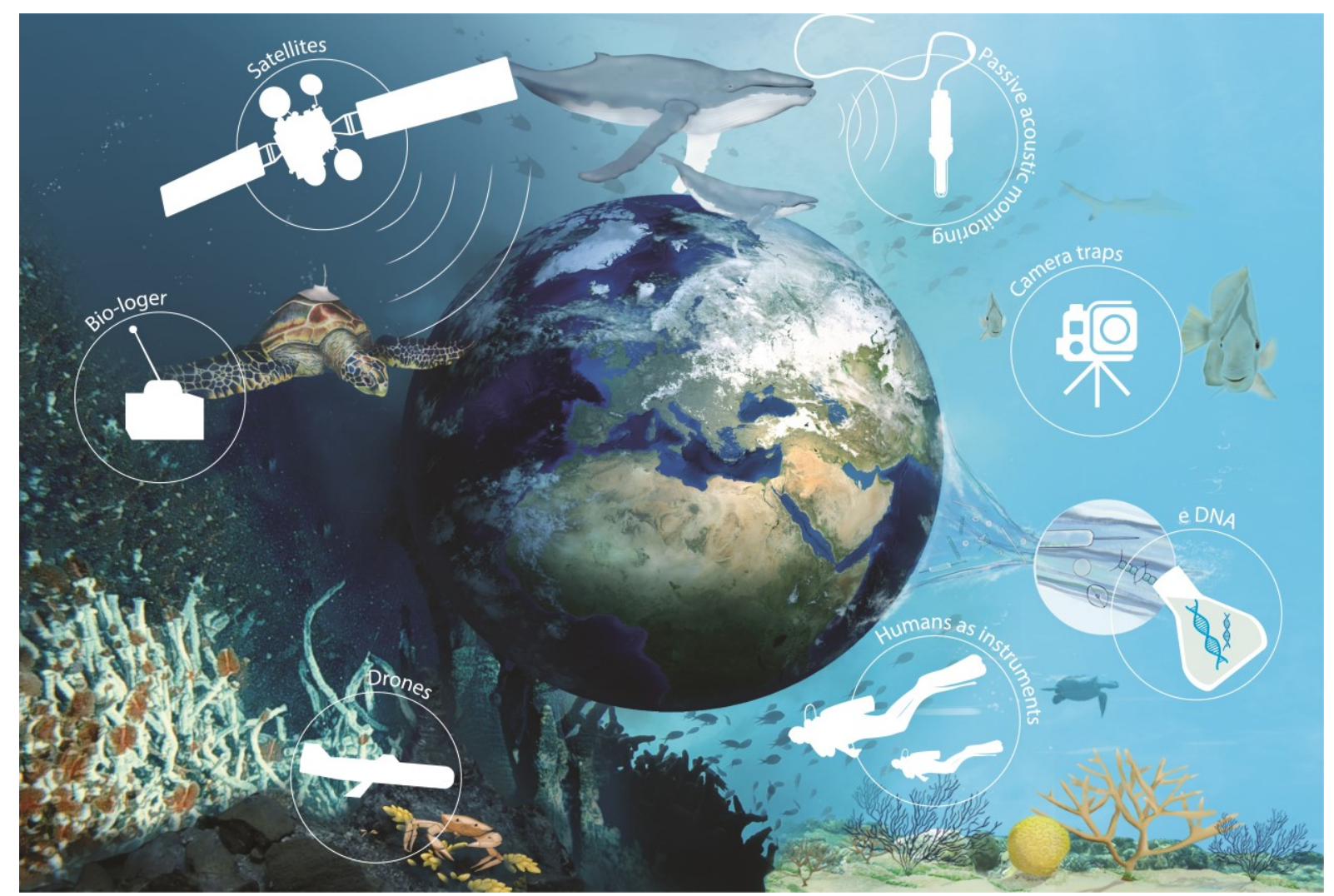


Figure 2: Each of the macroscope tools operates at different scales and resolutions, and contributes unique data to the observation of biodiversity across the planet.
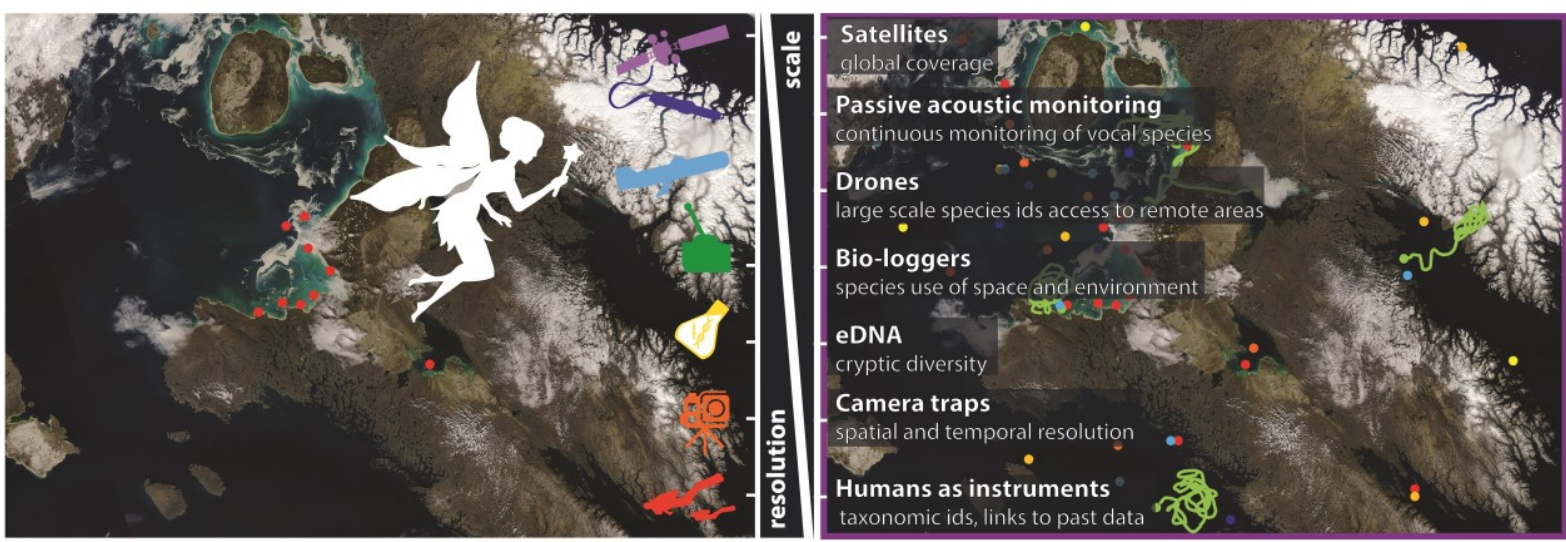